\title{
Role of ultrasonography in screening of spinal dysraphism in infants at risk
}

\author{
Nada Ahmed Hussein * (D, Khaled A. Ahmed, Noha Mohamed Osman and George Ezzat Elkess Yacoub
}

\begin{abstract}
Background: Spinal dysraphism (SD) encompasses congenital spinal defects that result from inappropriate fusion of the different midline osseous, mesenchymal, and neural elements. The primary tools for diagnosis of SD are both spinal ultrasonography (USG) and magnetic resonance imaging (MRI). Spinal USG is growingly being used as an initial screening modality with sensitivities and accuracies equivalent to those of MRI. Anorectal malformations (ARM) have ultimate association with many other congenital abnormalities, of which spinal dysraphism is one of the most common. The main aim of study was to assess the diagnostic accuracy of spinal USG as a screening modality in comparison with MRI in infants with closed spinal dysraphism. We also endeavored to highlight the associated spinal dysraphism radiological findings in patients with either ARM or back cutaneous stigmata.
\end{abstract}

Results: Our prospective diagnostic comparative study included 33 patients, all of whom underwent both MRI and USG. Both MRI and USG showed appreciable agreement in the assessment of spinal dysraphism. In comparison with the gold standard MRI, spinal USG revealed comparable diagnostic metrics: specificity (98.6-100\%), sensitivity (66.6-91.6\%), PPV (90-100\%) and NPV (94.1-98.7\%) in diagnosis of different types of spinal dysraphism. The main clinical presentation of nineteen patients was anorectal malformation (ARM), 11 of whom (57.9\%) had evidence of associated spinal dysraphism. The most common types of ARM were cloacal malformation, recto-urethral fistula, and rectal atresia with no fistula. On the other hand, sixteen patients were mainly presented with back cutaneous stigmata, 11 of whom (68.8\%) had associated spinal dysraphism. The most common presenting cutaneous stigmata were low back swelling and atypical dimples.

Conclusion: The front-line screening modality for infants with closed SD should be spinal USG, however, its main limitation is the restrained time window in the first 6 months of life. Infants with ARM should be screened for spinal anomalies, especially those with high and complex types. Infants with high-risk back cutaneous stigmata should be similarly screened, as well.

Keywords: Spinal dysraphism, Ultrasonography, Magnetic resonance imaging, Anorectal malformations

\section{Background}

Spinal dysraphism (SD) encompasses a wide range of congenital abnormalities that result from faultiness of the complex multi-step process of embryological development throughout the spinal axis during the 2nd and 6th weeks of gestation [1]. The lumbo-sacral spine (LSS) is the most frequent site for these spinal anomalies [2].

*Correspondence: nadaahmed@med.asu.edu.eg

Department of Radiodiagnosis, Faculty of Medicine, Ain Shams University, Cairo, Egypt
Spinal axis anomalies, including both the spine and spinal cord, are estimated to have an incidence of around 1-3/1000 live births [3]. The few past decades have shown a significant regression in the prevalence of SD, primarily owing to adequate supplementary folic acid, along with maternal nutrition, antenatal care, prenatal ultrasonography (USG), and genetic screening [4].

Spinal dysraphism is categorized into open and closed subtypes based on the presence or absence of the skin covering. The skin covering is absent in open spinal dysraphism (OSD) and the neural elements 
beneath are left exposed to the surrounding. Whereas, in closed spinal dysraphism (CSD) the neural elements are covered by intact skin [5].

The diagnosis of OSD is clinically obvious and postnatal USG screening should be avoided because of the high risk of infection, whereas CSD is much less apparent at birth [6]. It is usually made aware by the variable cutaneous stigmata, including abnormal hair tufts, skin pigmentation, cutaneous hemangiomas, sinus openings, or subcutaneous masses [7]. The associated relationship between cutaneous stigmata and CSD has been long described and relies on the intimacy of their embryological origin. The presence of cutaneous stigmata allows for timely identification of SD [2].

There is an analogous relation between patients with anorectal malformations (ARM) and associated congenital anomalies of the VACTERL spectrum. The spectrum of congenital anomalies incorporates spinal and/or vertebral defects (V), anorectal malformations (A), congenital cardiac anomalies (C), esophageal atresia/tracheoesophageal fistula (TE), renal and urinary abnormalities (R), and limb lesions (L). The association between spinal dysraphism and ARM has been reported to be up to $46 \%$. Hence, patients with ARM are screened at birth to detect possible associated SD anomalies. Neonates with ARM are usually screened by spinal USG and confirmed by spinal magnetic resonance imaging (MRI) [8].

Early identification of spinal dysraphism is crucial to avoid irreversible consequences such as neurological damage in tethered cord syndrome [9]. Neuro imaging of the spinal axis plays an immense role in the detection and classification of wide spectrum of SD anomalies [10].

Ultrasonography, being a safe portable bedside imaging tool that requires no sedation nor radiation, is rendered a valuable front-line screening modality in neonates with suspected spinal anomalies and is widely accepted by parents. The familiarity with the USG findings in neonates with spinal developmental anomalies is of great importance [7].

The lack of ossification of the posterior spinal elements before 6 months of age presents a superior acoustic window for the delineation of the spinal axis, its canal content, and surrounding tissues [1].

Magnetic resonance imaging is the gold standard for radiological imaging of spinal dysraphism, yet it is still limited by its high cost and restricted availability, as well as the requirement of sedation in most children. Regardless these limitations, MRI is still the most preferable imaging tool particularly in those patients with high pretest probability for SD [2].

The main objective of our study was to assess the diagnostic accuracy of spinal USG as a screening modality in comparison with MRI in infants with closed spinal dysraphism. We also endeavored to highlight the associated spinal dysraphism radiological findings in patients with either ARM or cutaneous stigmata.

\section{Methods \\ Study population}

This is a prospective comparative cross sectional diagnostic study that included 33 patients presented with clinical suspicion of SD. Patients of interest were recruited from out-patient clinic and in-patient wards of the Pediatrics, Obstetrics, and Pediatric neuro-surgery departments at our institution during the time period from January 2020 to November 2021.

\section{Inclusion criteria}

- Infants less than 6 months of age (or older with large bony spinal defect which permits passage of USG beam with proper visualization of intraspinal contents) presenting with back cutaneous stigmata, which include: High-risk dimples (greater than $5 \mathrm{~mm}$ in diameter and more than $2.5 \mathrm{~cm}$ above the anus), palpable subcutaneous mass, haemangioma/skin pigmentation, skin tags or tails, hairy patches, sinus tracts and patients with anorectal malformations, especially complex types.

\section{Exclusion criteria}

- Infants with open spinal dysraphism, infants older than 6 months of age with no large spinal defect (hindering proper visualization of intraspinal contents) and infants having contraindication to MRI.

\section{Study procedure}

The patients were subjected to thorough full history taking and detailed physical examination including: general examination (Scoliosis), local back examination (cutaneous stigmata), orthopaedic examination, neurological examination (urinary bladder, bowel). Any previous relevant studies were reviewed (Plain $\mathrm{x}$-ray LSS, dedicated anorectal study). The procedure was explained to the parents and/or guardian(s). Then, all patients underwent high resolution USG as well as MRI examinations. One specialized radiologist of 5 years' experience in pediatrics cross sectional imaging reviewed all MRI studies, and another specialized radiologist of 8 years' experience in pediatric USG underwent all spinal USG examinations; both were blind to patients' data and to the results of each other. Following Hughes et al. [11] and others [12, 
13], images of both USG and MRI were compared to each other's and the degree of agreement between different findings in both studies were classified into full (where all findings in MRI were identified in USG), partial (some findings in MRI were missed in USG) and no agreement (where all findings of MRI were missed by USG).

\section{Spinal USG examination}

We followed the AIUM (American Institute of Ultrasound in Medicine) Practice Parameters-Neonatal and Infant Spine, 2016.

\section{Equipment specifications}

Ultrasonography was performed utilizing (Samsung machine HM70A/GE machine LOGIQ P9), Real time USG scanners using high frequency linear array transducers, ranging from 9 to 12 megahertz $(\mathrm{MHz})$ in neonates. A curvilinear probe ( 3 to $9 \mathrm{MHz}$ ) was used if a greater field of view (FOV) was required or if the acoustic window access was limited in older infants.

\section{Patient positioning}

The examination was performed with the infant lying in the prone position (although the examination can also be performed in lateral decubitus). When necessary, either the prone reversed Trendelenburg position or the upright position, resulted in distension of the lower thecal sac cerebrospinal fluid (CSF) space and permitted adequate demarcation of the cauda equina region. The knees could be flexed toward the abdomen to allow for separation of the spinous processes and adequate assessment of the contents of the spinal canal. Infants were fed prior to the examination to lie quietly through the study.

\section{Technique}

The spinal cord was examined in both longitudinal and transverse planes. Transverse images were right and left labeled. Longitudinal scans were ideally acquired in mid sagittal planes. However, in older infants with more spine ossification, it was usually necessary to acquire scans in a slightly para sagittal planes parallel to the axis of the spinous processes. Adequate thick USG gel layer was used to assess the superficial soft tissue and skin surface for the presence of any tract. Sterile USG gel with a sterile probe cover was utilized in cases where the skin was not intact to avoid the risk of infection. Panoramic imaging views of the entire spinal canal were also really helpful in demonstrating a full anatomical overview along with the relationship between the spinal cord and the vertebral column, as well as highlighting the level of the conus within the theca.

\section{Image interpretation}

Normal spinal cord anatomy and the level of termination of the conus were determined, bearing in mind the correct enumeration of the vertebral body levels. The integrity of the cord was assessed. The echogenicity and the thickness of the filum terminale were examined. Subcutaneous masses, if present, were assessed and characterized as either cystic or fatty, and interrogated for any intrathecal extension. The subarachnoid space was investigated for a normal anechoic USG appearance along with intervening linear hyperechoic nerve roots as well as the traversing dentate ligaments. The subarachnoid, dural, and epidural spaces were all evaluated for abnormalities including dermoid, lipoma, abscess, and other masses. Cine and $\mathrm{M}$-mode examination were performed to depict the normal free oscillating movement of the terminal cord and nerve roots in concordance with the cardiac-related spinal CSF pulsations. The vertebral bodies, posterior neural elements, para vertebral muscles, and overlying skin were evaluated meticulously. Power and color Duplex imaging provided proper insight on the vascular anatomy and aided the diagnostic accuracy. The high association between spinal and renal abnormalities required that both kidneys be scanned in longitudinal and axial planes before ending the study.

\section{Spinal MRI examination \\ Equipment specifications}

Magnetic resonance imaging study was performed using a 1.5 Tesla machine (Achieva, Philips medical system, Eindhoven, Netherlands) using an 8-channel dedicated phased array coil. When necessary, infants were sedated to keep them as quiet as possible during the scan, in accordance with our Radiology and Anesthesia departmental guidelines.

\section{Patient positioning}

Infants were laid supine in the magnet during the procedure. Some infants with back swelling were made to lie prone or in lateral decubitus, particularly if the lesion was tender.

\section{Technique}

Imaging protocol included sagittal and axial images of the lumbar and sacral regions. Scans were performed using a FOV of $200-250 \mathrm{~mm}(\mathrm{~mm}), 265 \times 265$ matrix sizes, $3 \mathrm{~mm}$ slice thickness, slice interval of $0.5-1.0 \mathrm{~mm}$.

Turbo spin-echo sequences were acquired using the following parameters: 
T1 weighted image (WI): Repetition time (TR)/Echo time (TE) $/$ Flip Angle $=550 / 9.4 / 90^{\circ}$.

T2 weighted image (WI): TR/TE/Flip Angle $=4000 / 110 / 150^{\circ}$.

Sagittal STIR (Short Tau Inversion Recovery sequences) sequences were acquired using TR of $3000 \mathrm{~ms}$ (ms) and TE of $40 \mathrm{~ms}$.

An additional T2WI coronal sequence was also acquired in cases with abnormal spinal curvature and vertebral segmentation defects, as well as in cases of diastematomyelia.

Sagittal balanced Fast Field Echo (b-FFE) sequence was added using the following parameters:

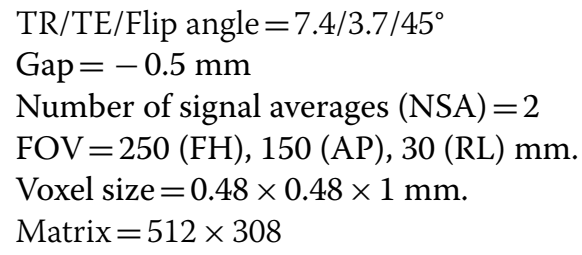

\section{Image interpretation}

Classification of dysraphism, site and extent of dysraphism, lipoma-placode interface location, position of conus termination and its shape, presence of cord tethering/stretching, thickening and integrity of filum terminale, integrity of the dura, presence of hydromyelia/ syrinx, presence of 2 hemicords, presence of dorsal dermal sinus \pm associated meningitis, thorough full evaluation of the lesions' contents (fluid, fat, soft tissue, and neural elements) and extent (intra, extra, or both intra and extraspinal), as well as the elements passing through the dural and vertebral defects, vertebral anomalies such as, segmentation anomalies, sacral agenesis, posterior vertebral arch defects, Bladder and bowel involvement (associated neurogenic bladder/anorectal malformation).

\section{Duration of examination}

15 minutes.

\section{Ethical considerations}

The study was conducted in accordance with the stipulations of the ASU ethical and scientific committee. The privacy of participants and confidentiality of data were guaranteed throughout the various phases of the study.

\section{Statistical analysis}

Data were collected, revised, coded and entered to the Statistical Package for Social Science (IBM SPSS) version 23. The quantitative data with parametric distribution were presented as mean, standard deviations and ranges while with nonparametric were presented as median with inter-quartile range (IQR). Also, qualitative variables were presented as number and percentages.

The comparison between groups regarding qualitative data was done by using Chi-square test and/or Fisher exact test when the expected count in any cell found less than 5.

Kappa agreement was used to assess the agreement between MRI and USG with its 95\% confidence interval.

Receiver operating characteristic curve (ROC) was used in the form of qualitative mode to assess sensitivity, specificity, positive predictive value (PPV), negative predictive value (NPV) and accuracy of USG taking MRI as a gold standard.

The confidence interval was set to $95 \%$ and the margin of error accepted was set to $5 \%$. So, the $P$ value was considered significant as the following:

$$
\begin{aligned}
& P \text { value }>0.05: \text { Non-significant }(\mathrm{NS}) \\
& P \text { value }<0.05: \text { Significant }(\mathrm{S}) \\
& P \text { value }<0.01: \text { Highly significant }(\mathrm{HS})
\end{aligned}
$$

\section{Results}

\section{Demographics of study population}

Our study encompassed thirty-three patients, seventeen males (51.5\%) and sixteen females (48.5\%). Their age group ranged from 9 days to 2 years with a mean age of 5.3 months.

\section{Distribution of study population}

The distribution of the studied patients was categorized according to each of following: their main clinical presentation, non-spinal associated anomalies, and spinal segment(s) involvement.

As represented in Table 1 and shown in Fig. 1, the main clinical presentation of our study population was either back cutaneous stigmata (16 patients) and/or ARM (19 patients), classified and enumerated accordingly. Of the aforementioned 16 patients with cutaneous stigmata, 4 patients had multiple concurrent cutaneous lesions. Whereas of the total 33 patients, 2 patients were presented with both cutaneous stigmata (both of whom had back swellings, one fatty and the other cystic) and ARM (both of whom had a rectourethral fistula) (Figs. 2, 3).

Non-spinal associated anomalies confronted in our study were renal anomalies (40\%), hydrocephalus (20\%), lower limb anomalies (10\%), genital anomalies (10\%), cardiac anomalies (10\%), and motor anomalies (5\%) (Figs. 3, 4).

In our study, lumbosacral involvement was most frequently encountered in 7 patients (35\%), after which was 
Table 1 Distribution of study population in terms of main clinical presentation

\begin{tabular}{lll}
\hline Main clinical presentation & \multicolumn{2}{l}{ Total no.=33 } \\
\cline { 2 - 3 } Back cutaneous stigmata & Number & Percentage (\%) \\
\hline Hemangioma & 1 & $(3.0 \%)$ \\
Skin discoloration (pigmentation) & 4 & $(12.1 \%)$ \\
Dimple & 6 & $(18.2 \%)$ \\
Swelling & 6 & $(18.2 \%)$ \\
$\quad$ Fatty & 2 & $(6.1 \%)$ \\
$\quad$ Cystic & 4 & $(12.1 \%)$ \\
Hair tuft & 3 & $(9.1 \%)$ \\
Skin tag & 1 & $(3.0 \%)$ \\
ARM & & \\
Rectourethral fistula & 4 & $(12.1 \%)$ \\
Rectal atresia & 4 & $(12.1 \%)$ \\
Cloacal malformation & 5 & $(15.2 \%)$ \\
Vestibular fistula & 3 & $(9.1 \%)$ \\
Perineal fistula & 2 & $(6.1 \%)$ \\
Rectovaginal fistula & 1 & $(3.0 \%)$ \\
\hline
\end{tabular}

the lumbar spine in 6 patients (30\%), sacrococcygeal in 5 patients $(25 \%)$, and lastly dorsolumbar in 2 patients $(10 \%)$ (Figs. 4, 5).
Prevalence and subtypes of CSD in our study population In our study population, 20 patients $(60.6 \%)$ had spinal dysraphism, while 13 (39.4\%) screened infants showed no evidence of spinal dysraphism.

Table 2 displays the distribution of the study population according to the subtype of spinal dysraphism.

\section{Association between SD and each type of ARM}

Out of the 19 patients presented with ARM, 11 patients (57.9\%) had spinal dysraphism, while 8 (42.1\%) showed no evidence of spinal dysraphism.

Table 3 represents the association between each subtype of ARM and SD and their relative significance using Chi square test. All the ARM subtypes showed no significant relation with SD $(P$ value $>0.05)$.

\section{Association between SD and cutaneous stigmata}

Out of the 16 patients presented with cutaneous stigmata, 11 patients $(68.8 \%)$ had spinal dysraphism while 5 (31.2\%) showed no evidence of spinal dysraphism.

Table 4 represents the association between each subtype of back cutaneous stigmata and SD and their relative significance using Chi square test. Out of the different subtypes, only back swelling revealed a significant relation with SD (Pvalue 0.029) (Figs. 2, 3, 4, 6).

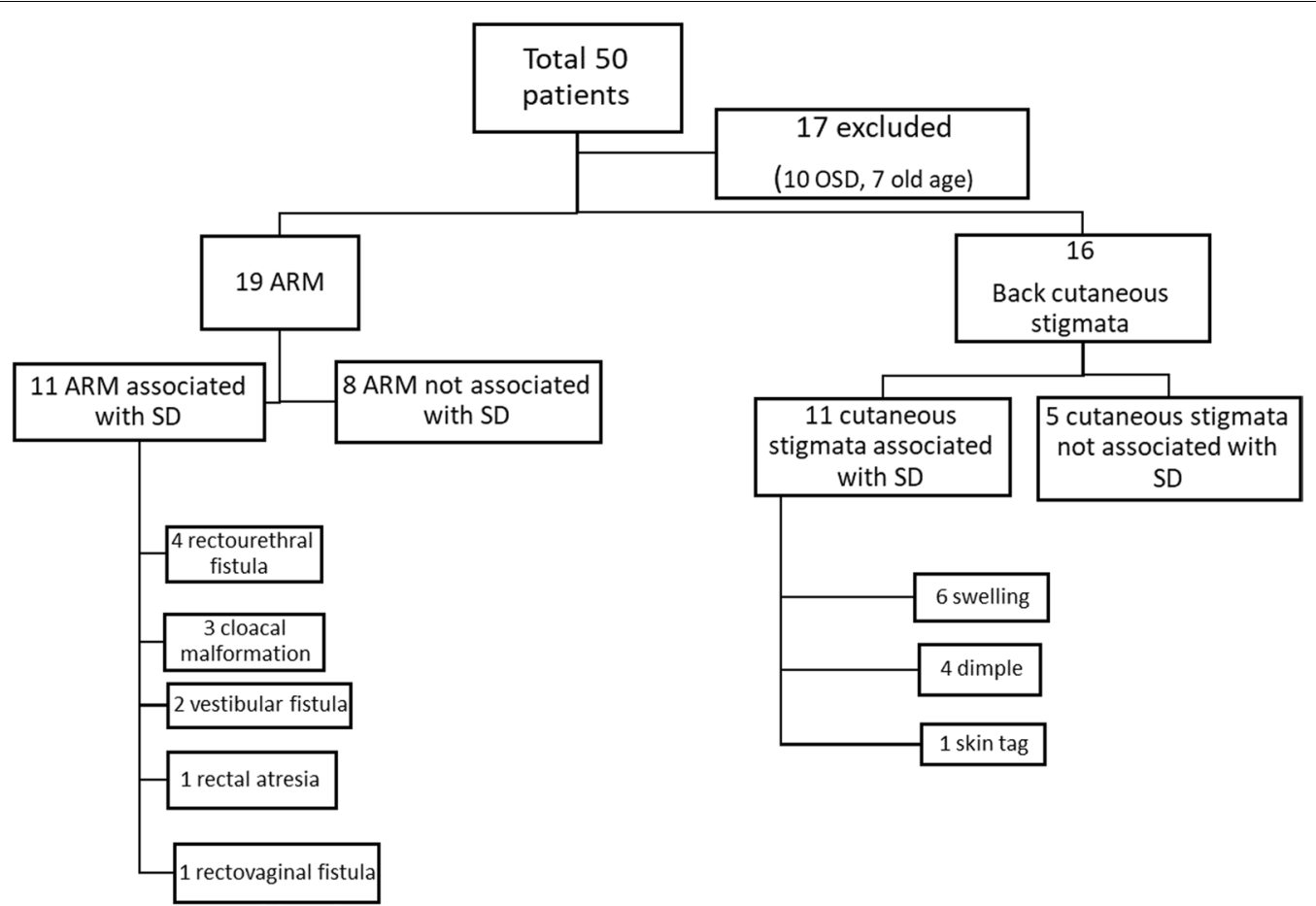

Fig. 1 Diagnostic flow chart of the study population. Note 2 patients were presented with both ARM and back cutaneous stigmata. ARM anorectal malformation, SD spinal dysraphism, OSD open spinal dysraphism 


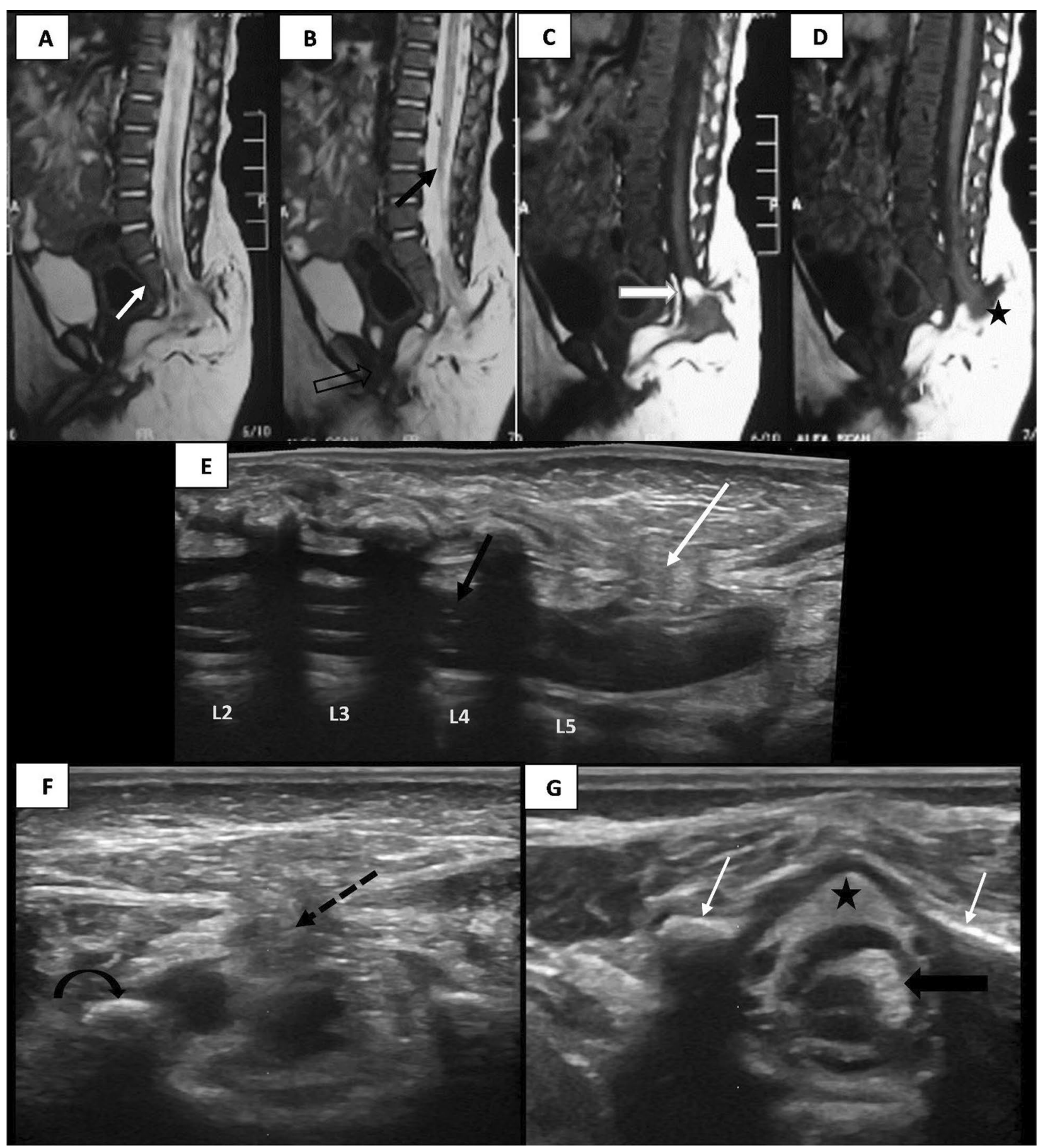

Fig. 2 One-month-old male infant presented with low back fatty swelling and ARM. A Sagittal T2WI showing agenesis of S3, 4, 5 sacral elements and coccyx in keeping with sacral agenesis type II (white arrow). B Midline sagittal T2WI showing low lying conus medullaris ending at level of L3-4 disk yet with normal tapering appearance (black arrow), note also evidence of high-level ARM; above puborectalis muscle, with rectourethral fistula (Black empty arrow). C Sagittal T1WI showing herniation of subcutaneous fat through dural defect into spinal canal (white arrow). D Sagittal T1WI showing lipoma-placode interface outside spinal canal (star). E Sagittal USG image showing conus medullaris tip at level of L4 (black arrow), with subcutaneous fatty mass seen herniating into spinal canal (white arrow). F Axial USG image showing herniation of neural placode (dashed arrow) outside the confinement of spinal canal (curved black arrow, lamina). G Axial USG image at level of L4 showing lamina (white arrows), epidural fat (star) and cauda equina nerves (black arrow). Type of spinal dysraphism: Lipomyelomeningeocele with partial sacral agenesis 


\section{Agreement between spinal USG and MRI findings in diagnosis of CSD}

Regarding the degree of agreement between USG and MRI there were 28 cases $(84.8 \%)$ that showed full agreement. Partial agreement was seen in 3 cases $(9 \%)$ all of which included missed USG findings, as follows: complicated meningitis in a case with dermal sinus tract (DST), spinal lipoma associated with a case of caudal regression syndrome (CRS), and neural tissue within the herniating sac in a case of lipomyelomeningocele. Whereas there was no agreement whatsoever in two cases $(6.1 \%)$ where USG failed to show any of the findings demonstrated by MRI, including a case with limited dorsal myeloschisis (LDM) and another with persistent terminal ventricle.

\section{Accuracy of USG compared to MRI in the detection of both spinal cord and bony element anomalies in patients with spinal dysraphism}

Tables 5 and 6 display the agreement between USG and MRI in the diagnosis of each subtype of spinal dysraphism and segmentation/vertebral spine anomalies, respectively. As a rule of thumb, $(\kappa=1)$ indicates perfect agreement, $(0.8-1)$ excellent agreement, $(0.6-0.8)$ good agreement, $(0.4-0.6)$ fair agreement, $(0-0.4)$ poor agreement, and $(\kappa=0)$ indicates agreement by chance alone.

Tables 7 and 8 reveal the significance of the relation between USG and MRI in the diagnosis of each type of spinal dysraphism and segmentation/vertebral spine anomalies, respectively. Significant $P$ values of less than 0.001 was exhibited in all subtypes of spinal dysraphism as well as segmentation/vertebral spine anomalies, as tabulated. Hence, there is strong evidence that agreement between USG and MRI in diagnosis of different types of spinal dysraphism did not occur by chance alone.

The overall accuracy of spinal USG compared to MRI in the diagnosis of spinal dysraphism were as follows: specificity ranging from 98.6-100\%, sensitivity ranging from 66.6-91.6\%, PPV ranging from $90-100 \%$, and
NPV ranging from 94.1-98.7\%. There was compelling overall accuracy of the detailed imaging findings of USG compared to MRI $(\kappa=0.973)$.

\section{Discussion}

The spinal segment involvement encountered in our study (as forementioned in the results above), were comparably concordant with Tawfik et al. [12] and Kommana et al. [10] whom both showed that the LSS was the most commonly affected region in $71.1 \%$ and $28.5 \%$, followed by the dorsolumbar spine in $17.8 \%$ and $21.4 \%$, and the sacrococcygeal spine in $11.1 \%$ and $14 \%$, respectively. Whereas Dhingani et al. [13] showed that the LSS was the most common involved in $52.6 \%$ of patients, followed by the sacrococcygeal spine in $34.2 \%$.

On the contrary to the Tawfik et al. [12], Kommana et al. [10], and Dhingani et al. [13] studies which included cases of both open and closed SD, we only included cases of CSD to be more precise and since OSD actually requires no imaging.

The most common subtypes of SD encountered in our study are presented in Table 2. Both Tawfik et al. [12] and Dhingani et al. [13] showed comparable similar prevalences of the forementioned CSD subtypes, apart from the mere $6.6 \%$ for tethered cord in Tawfik et al. [12] as opposed to the compelling $60 \%$ in our own cohort.

Non-spinal associated anomalies confronted in our study varied in diversity and frequentness compared to other studies as discussed in detail in results section. Ruangtrakool et al. [14] documented fecal incontinence, urinary incontinence, motor symptoms, gait abnormalities, and scoliosis, in order of frequency. Whereas Tawfik et al. [12] documented neurological abnormalities, urinary incontinence, hydrocephalus, and Chiari malformation, in order of frequency.

Many of these associated non-spinal anomalies can probably be attributable to the tethered cord syndrome, whereby the fixation of the filum terminale causes secondary traction injury unto the spinal cord.

Our study, along with Ruangtrakool et al. [14], Oh et al. [15] and Jehangir et al. [16], implemented the Krickenbeck's classification system for ARMs.

\footnotetext{
(See figure on next page.)

Fig. 3 Four-month-old male infant presented with ARM, lower back cystic swelling, and lower limb anomalies. A Plain AP radiograph of pelvis showing pronounced structural skeletal caudal defect in the form of hypoplastic left iliac and ischial bones, absent femur on left side with only femoral head and neck visualized on right side. B Axial T2WI showing dilated central canal (thin black arrow) within a dilated subarachnoid space herniating outside confines of spinal canal (thick black arrow) through defect in posterior element of S1 vertebra. Note also ectopic location of left testis in left aspect of anterior pelvic wall (white arrow) which corresponds to diffusion restriction seen in $\mathbf{C}$. D Catheterization of single opening in upper perineum discharging urine revealed contrast opacification of distal bowel rectal loop with non-visualized urinary bladder in keeping with rectourethral fistula. E Panoramic sagittal USG image showing tethered cord with herniating dilated central canal (thin white arrow) within a meningocele (thick white arrow) through defect in upper sacral vertebra giving cyst within cyst appearance. Type of spinal dysraphism: Terminal myelocystocele
} 


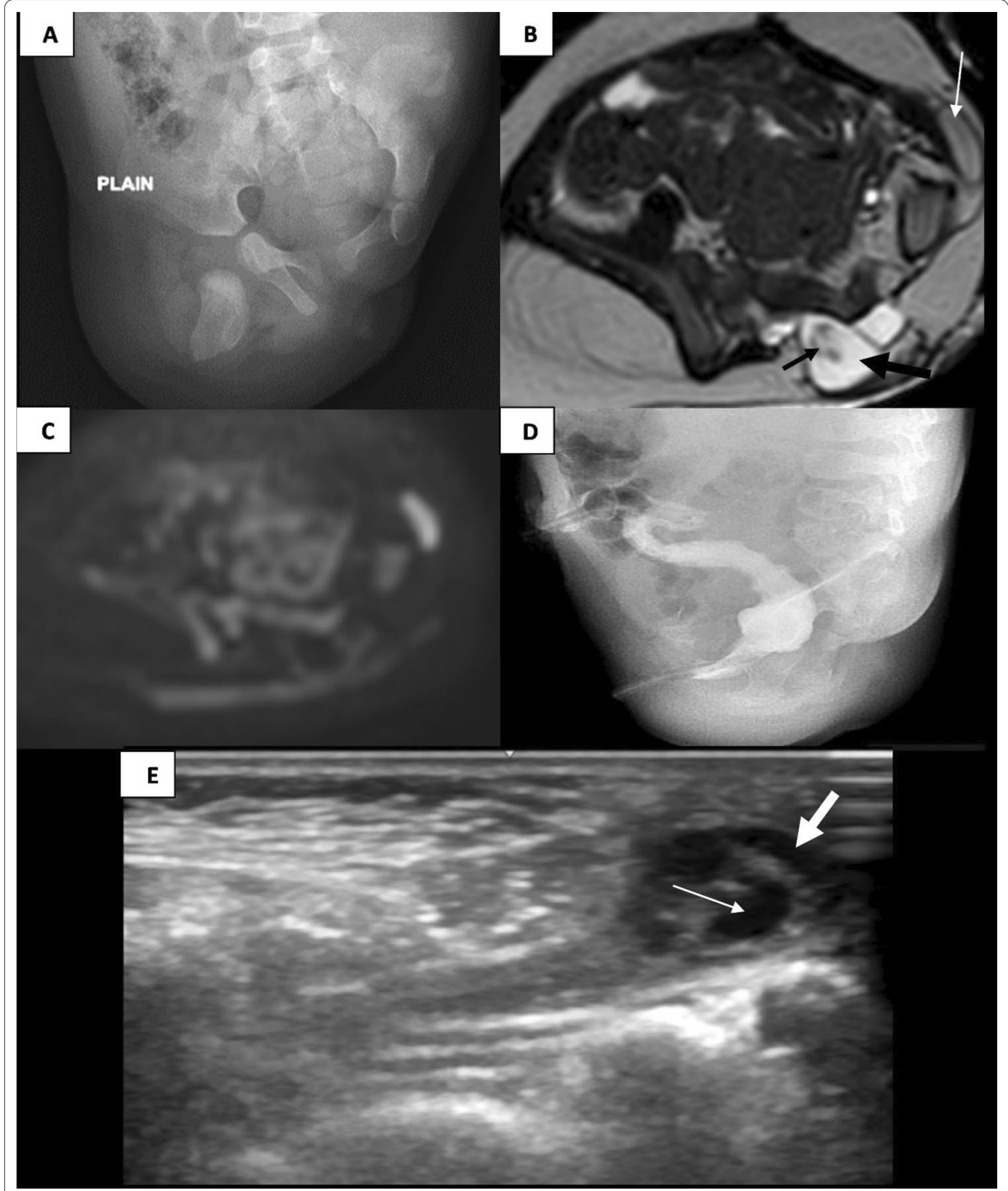

Fig. 3 (See legend on previous page.) 


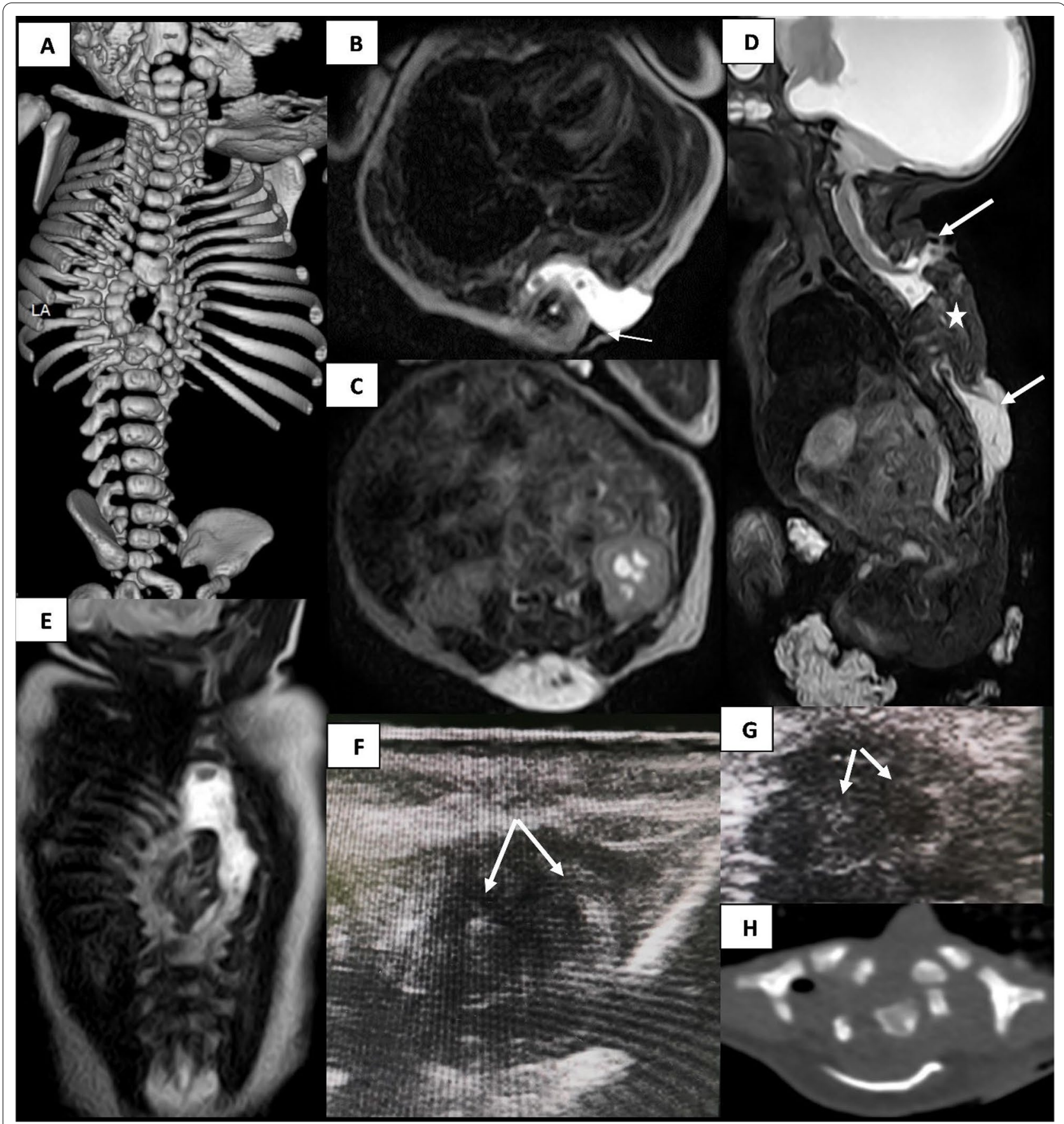

Fig. 4 Twenty-day-old female infant presented with multiple back masses, 2 cystic and one solid at both dorsal and lumbar levels. A 3D reconstruction image of bony spine showing multilevel segmentation anomalies with complete splitting of lower 6 thoracic vertebrae into 2 separate spinal canals. B Axial T2WI at upper dorsal level showing 2 hemicords herniating into two sacs in keeping with hemi-myelomeningoceles, on the left side shows focal rupture (white arrow). C Axial T2WI at upper lumbar level showing another intact myelomeningocele containing two hemi cords, note left sided hydronephrosis. D Sagittal fat suppressed image of whole spine showing upper dorsal and lumbar myelomeningoceles (white arrows) as well as lower dorsal heterogenous fat containing lesion (white star), note associated hydrocephalus. E Coronal T2Wl showing segmental lower dorsal splitted bony elements with heterogenous mass in-between containing both fatty and bony elements histopathologically proven to be teratoma. F, G Bed side axial USG images showing two hemicords within single dural sheath (white arrows). H Axial CT image bone window at lower dorsal level showing splitted spinal canal. Type of spinal dysraphism: Split notochord (Diastematomyelia) with myelomeningoceles 


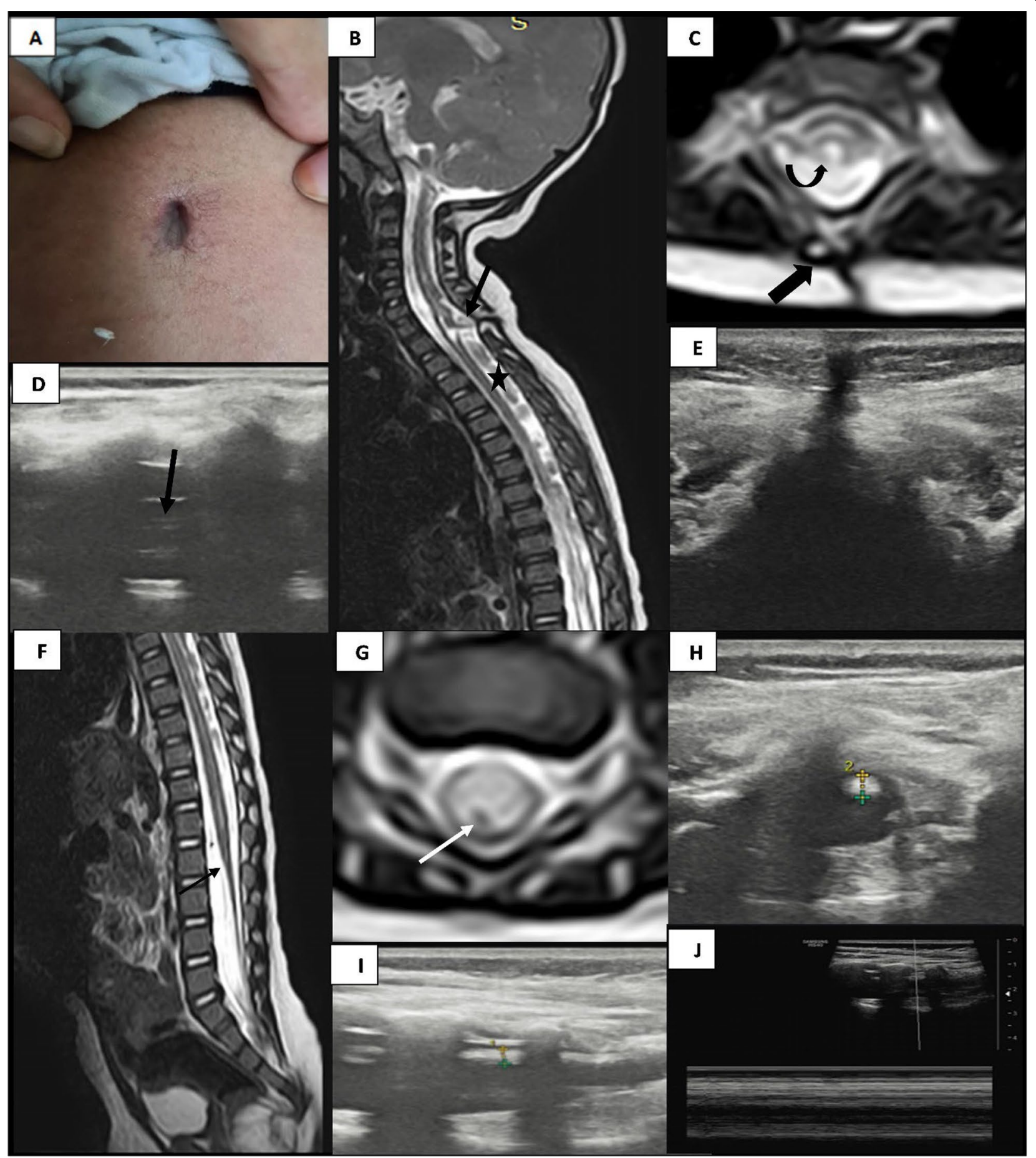

Fig. 5 Eight-month-old male infant presented with upper dorsal atypical skin dimple (crater) associated with cardiac congenital anomaly (TGA) A An upper dorsal cutaneous deep wide dimple (crater) with mild hypertrichosis. B Sagittal MRI T2WI showing fibrous tract extending from skin surface at level of D1/D2 vertebrae passing deeply into spinal canal with tethering and slight tenting of spinal cord at that level (black arrow), dorsal CSF flow artifact (star). C Axial MRI T2WI showing the fibrous tract passing though spinal bifida of D2 vertebra (black arrow) with minimal syrinx at that level (curved black arrow). D Sagittal USG image showing minimally dilated central canal (black arrow). E Axial USG image showing the fibrous tract extending from skin surface into spinal canal. F Sagittal T2Wl at level of lumbar spine showing conus tip at level of L2 vertebrae (black arrow) with relatively thickened filum terminale. G Axial T2WI showing thickened filum terminale (white arrow). H, I Axial and Sagittal USG images showing thickened echogenic filum terminale measuring $2.1 \mathrm{~mm}$. J M mode USG image at L5-S1 level showing absent movement of nerve roots. Type of spinal dysraphism: Dorsal LDM with focal syrinx and tight filum terminale 
Table 2 Distribution of study population regarding subtypes of closed spinal dysraphism

\begin{tabular}{lll}
\hline Spinal dysraphism type & $\begin{array}{l}\text { Number } \\
(\mathbf{S D}=\mathbf{2 0})\end{array}$ & Percentage (\%) \\
\hline Tethered cord & 12 & $(60 \%)$ \\
Lipomyelocele & 1 & $(5 \%)$ \\
Lipomyelomeningocele & 2 & $(10 \%)$ \\
Meningocele & 1 & $(5 \%)$ \\
Terminal myelocystocele & 2 & $(10 \%)$ \\
Spinal lipoma & 3 & $(15 \%)$ \\
Lipoma of the filum terminale & 3 & $(15 \%)$ \\
LDM & 3 & $(15 \%)$ \\
Dermal sinus tract & 1 & $(5 \%)$ \\
Tight filum terminale & 2 & $(10 \%)$ \\
Persistent terminal ventricle & 1 & $(5 \%)$ \\
Caudal regression syndrome & 3 & $(15 \%)$ \\
Diastematomyelia & 1 & $(5 \%)$ \\
\hline
\end{tabular}

In our study, we found that $57.9 \%$ of the screened patients with ARMs had coexistent spinal dysraphism. This prevalence ranged $16.2 \%$ in Ruangtrakool et al. [14], 22\% in Oh et al. [15] and 42\% in Esposito et al. [17] studies.

The most common subtypes of ARM encountered in our study (as detailed in Table 1) were similar to ARM subtypes encountered in other studies conducted by Ruangtrakool et al. [14], Jehangir et al. [16], and Minneci et al. [18].

In our study, the most common subtype of ARM associated with coexistent spinal dysraphism are enumerated in Table 3. In comparison with other similar studies [14, $16,18]$ the most common ARM subtypes associated with $\mathrm{SD}$ were the cloacal malformation and rectourethral fistulas, whereas the least common was the perineal fistula. However, these studies differed from ours, in showing a highly common association between the rectovesical fistula, which was not included in our study population, and SD.

The most common subtypes of SD coexisting in these patients with ARM, in both our study and other studies $[14,18]$, were tethered cord and segmentation/vertebral spine anomalies.

Spinal dysraphism has been reported to frequently coexist with cutaneous stigmata, ranging from as low as $5 \%$ in Resmi et al. [19] and up to $26 \%$ and $33 \%$ in Shields et al. [20] and O'Neil et al. [21], respectively. However, the wide variation in the morphological appearances of the lumbosacral and coccygeal regions along with the sparsity of the literature regarding the predictive value of these variations, creates a diagnostic dilemma when it comes to screening neonates [9]. On the contrary, a vast majority of patients (about $50-80 \%$ ) with SD are

Table 3 Association between each type of ARM and spinal dysraphism and its significance

\begin{tabular}{|c|c|c|c|c|c|}
\hline ARM & $\begin{array}{l}\text { No spinal dysraphism } \\
\text { No. }=13\end{array}$ & $\begin{array}{l}\text { Spinal dysraphism } \\
\text { No. }=20\end{array}$ & Test value & $P$ value & Sig. \\
\hline \multicolumn{6}{|c|}{ Rectourethral fistula } \\
\hline No & 13 (100.0\%) & $16(80.0 \%)$ & $2.959^{*}$ & 0.085 & NS \\
\hline Yes & $0(0.0 \%)$ & $4(20.0 \%)$ & & & \\
\hline \multicolumn{6}{|c|}{ Rectal atresia } \\
\hline No & $10(76.9 \%)$ & $19(95.0 \%)$ & $2.417^{*}$ & 0.120 & NS \\
\hline Yes & $3(23.1 \%)$ & $1(5.0 \%)$ & & & \\
\hline \multicolumn{6}{|c|}{ Cloacal malformation } \\
\hline No & $11(84.6 \%)$ & $17(85.0 \%)$ & $0.001^{*}$ & 0.976 & NS \\
\hline Yes & $2(15.4 \%)$ & $3(15.0 \%)$ & & & \\
\hline \multicolumn{6}{|c|}{ Vestibular fistula } \\
\hline No & $12(92.3 \%)$ & $18(90.0 \%)$ & $0.051^{*}$ & 0.822 & NS \\
\hline Yes & $1(7.7 \%)$ & $2(10.0 \%)$ & & & \\
\hline \multicolumn{6}{|c|}{ Perineal fistula } \\
\hline No & $11(84.6 \%)$ & $20(100.0 \%)$ & $3.275^{*}$ & 0.070 & NS \\
\hline Yes & $2(15.4 \%)$ & $0(0.0 \%)$ & & & \\
\hline \multicolumn{6}{|c|}{ Rectovaginal fistula } \\
\hline No & $13(100.0 \%)$ & $19(95.0 \%)$ & $0.670^{*}$ & 0.413 & NS \\
\hline Yes & $0(0.0 \%)$ & $1(5.0 \%)$ & & & \\
\hline
\end{tabular}

$P$ value $>0.05$ : non significant; $P$ value $<0.05$ : significant; $P$ value $<0.01$ : highly significant

${ }^{*}$ Chi-square test 
Table 4 Association between each type of back cutaneous stigmata and spinal dysraphism and its significance

\begin{tabular}{|c|c|c|c|c|c|}
\hline Skin stigmata & $\begin{array}{l}\text { No spinal dysraphism } \\
\text { No. }=13\end{array}$ & $\begin{array}{l}\text { Spinal dysraphism } \\
\text { No. }=20\end{array}$ & Test value & $P$ value & Sig. \\
\hline \multicolumn{6}{|l|}{ Hemangioma } \\
\hline No & $13(100.0 \%)$ & 19 (95.0\%) & $0.670^{*}$ & 0.413 & NS \\
\hline Yes & $0(0.0 \%)$ & $1(5.0 \%)$ & & & \\
\hline \multicolumn{6}{|c|}{ Skin discoloration } \\
\hline No & $10(76.9 \%)$ & 19 (95.0\%) & $2.417^{*}$ & 0.120 & NS \\
\hline Yes & $3(23.1 \%)$ & $1(5.0 \%)$ & & & \\
\hline \multicolumn{6}{|l|}{ Dimple } \\
\hline No & $11(84.6 \%)$ & 16 (80.0\%) & $0.113^{*}$ & 0.737 & NS \\
\hline Yes & $2(15.4 \%)$ & $4(20.0 \%)$ & & & \\
\hline \multicolumn{6}{|l|}{ Swelling } \\
\hline No & $13(100.0 \%)$ & $14(70.0 \%)$ & $4.767^{*}$ & 0.029 & $S$ \\
\hline Yes & $0(0.0 \%)$ & $6(30.0 \%)$ & & & \\
\hline \multicolumn{6}{|l|}{ Type of swelling } \\
\hline No & 13 (100.0\%) & $14(70.0 \%)$ & $4.767^{*}$ & 0.092 & NS \\
\hline Fatty & $0(0.0 \%)$ & $2(10.0 \%)$ & & & \\
\hline Cystic & $0(0.0 \%)$ & $4(20.0 \%)$ & & & \\
\hline \multicolumn{6}{|l|}{ Hair tuft } \\
\hline No & $11(84.6 \%)$ & 19 (95.0\%) & $1.028^{*}$ & 0.311 & NS \\
\hline Yes & $2(15.4 \%)$ & $1(5.0 \%)$ & & & \\
\hline \multicolumn{6}{|l|}{ Skin tag } \\
\hline No & $13(100.0 \%)$ & 19 (95.0\%) & $0.670^{*}$ & 0.413 & NS \\
\hline Yes & $0(0.0 \%)$ & $1(5.0 \%)$ & & & \\
\hline
\end{tabular}

$P$ value $>0.05$ : non significant; $P$ value $<0.05$ : significant; $P$ value $<0.01$ : highly significant

${ }^{*}$ Chi-square test

presented with cutaneous stigmata, as documented by Shields et al. [20] and Choi et al. [22]. This was in concordance with the $55 \%$ confronted in our study cohort.

In our study population, 16 patients had cutaneous stigmata, who are further categorized in Table 1. The 6 patients with dimples were further categorized as 2 isolated cases and 4 associated with other lesions ( 1 with a hair tuft, 1 with skin discoloration, 1 with both hair tuft and skin discoloration, and 1 with a hemangioma). Other studies, such as Resmi et al. [19], included many other subtypes of cutaneous stigmata in their study, including café au lait macules, melanocytic and sebaceous nevi, and aplasia cutis.

Spinal dysraphism was coexistent in 11 out of the 16 forementioned patients in our cohort. All the 6 patients with back swellings were associated with SD (1 meningocele, 2 terminal myelocystoceles, 1 teratoma + myelomeningeocele, 1 lipomyelocemingocele, and 1 lipomyelocele). While only 4 out of the 6 patients with dimples were associated with SD (1 dorsal sinus tract, 1 limited dorsal myeloschisis, 1 limited dorsal myeloschisis + intradural lipoma, 1 limited dorsal myeloschisis + tight filum terminale). The single patient with a skin tag was associated with a spinal lipoma.

Resmi et al. [19] revealed meningocele as the most common spinal anomaly. While Shields et al. [20], O’Neil et al. [21], and Choi et al. [22] revealed that low lying conus medullaris and fatty filum terminale were the most common encountered SD subtypes.

Regarding combined cutaneous stigmata, found in 4 patients of our study cohort ( 3 of whom had two stigmata and 1 had three), we revealed a significantly higher association with SD in patients with combined stigmata rather than single stigmata. This was in concordance with most of the other studies [19-22].

With sensitivities comparable to those of MRI, spinal USG is growingly being implemented as an initial screening modality in SD [12].

We evaluated the diagnostic accuracy of USG in screening patients with spinal dysraphism by comparing its results with spinal MRI. This is because spinal MRI is well known to be the gold standard in examining the spine and has been proven by Dhingani al. [13] to show a $100 \%$ correlation with operative findings. 


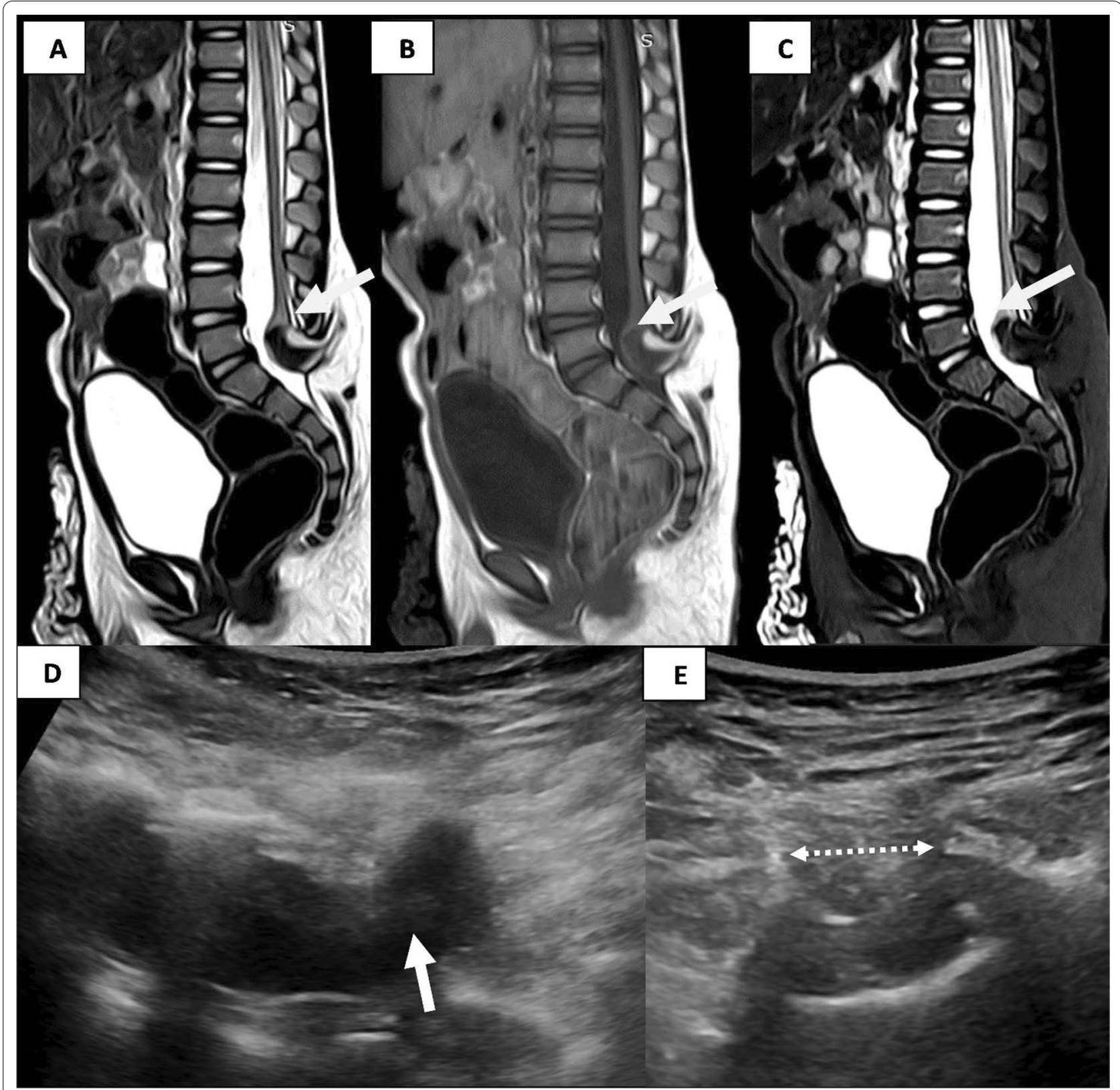

Fig. 6 Two-year-old male infant presented with low back fatty swelling since birth. A Sagittal T2WI, B Sagittal T1WI, C Sagittal fat suppressed images showing tethered cord ending at level of $L 5$ with a subcutaneous fatty mass extending into spinal canal through non fused spinous process of $L 5$, S1 and S2 as well as dural defect with lipoma placode interface seen within spinal canal (white arrows in $\mathbf{A}, \mathbf{B}$ and $\mathbf{C}$ ), a hypointense lesion is seen at the interface likely fibrous/calcified elements. D Sagittal USG image showing tethered cord at level of L5 (white arrow). E Axial USG image at level of L5 showing non fused spinous process with herniation of subcutaneous fat into spinal canal. Type of spinal dysraphism: Lipomyelocele

We concluded from our study that USG showed comparable accuracy to MRI, with a $100 \%$ specificity, $81.4 \%$ sensitivity, 100\% PPV, and 97\% NPV. These diagnostic accuracy metrics were comparably concordant with Tawfik et al. [12] revealing $94.5 \%$ specificity, $81.8 \%$ sensitivity, 84.3\% PPV, 86.7\% NPV; Jehangir et al. [16] revealing $91 \%$ sensitivity, $75 \%$ specificity, 80\% PPV, and 88\% NPV; and Elmesallamy et al. [23] revealing 100\% specificity and $83.3 \%$ sensitivity compared to gold standard MRI.

Regarding the degree of agreement (full, partial, and no agreement) between the USG and MRI findings, as detailed in our forementioned results, we revealed comparable results to other studies $[10,12,13]$ conducting the same categorization of agreement. Whereby we 
Table 5 Detailed agreement between USG and MRI findings regarding each subtype of spinal dysraphism

\begin{tabular}{|c|c|c|c|c|c|}
\hline $\begin{array}{l}\text { Type of spinal } \\
\text { dysraphism }\end{array}$ & $\begin{array}{l}\text { MRI } \\
\text { No. (\%) }\end{array}$ & $\begin{array}{l}\text { Ultrasound } \\
\text { No. (\%) }\end{array}$ & Test value & $P$ value & Kappa agreement $(95 \% \mathrm{Cl})$ \\
\hline \multicolumn{6}{|l|}{ Tethered cord } \\
\hline No & $8(40.0 \%)$ & $9(45.0 \%)$ & $0.102^{*}$ & 0.749 & 0.898 (0.704 to 1.000$)$ \\
\hline Yes & $12(60.0 \%)$ & $11(55.0 \%)$ & & & \\
\hline \multicolumn{6}{|l|}{ Lipomyelocele } \\
\hline No & $19(95.0 \%)$ & $19(95.0 \%)$ & $0.000^{*}$ & 1.000 & $1.000(1.000$ to 1.000$)$ \\
\hline Yes & $1(5.0 \%)$ & $1(5.0 \%)$ & & & \\
\hline \multicolumn{6}{|c|}{ Lipomyelomeningocele } \\
\hline No & $18(90.0 \%)$ & $18(90.0 \%)$ & $0.000^{*}$ & 1.000 & 1.000 (1.000 to 1.000$)$ \\
\hline Yes & $2(10.0 \%)$ & $2(10.0 \%)$ & & & \\
\hline \multicolumn{6}{|l|}{ Meningocele } \\
\hline No & $19(95.0 \%)$ & $19(95.0 \%)$ & $0.000^{*}$ & 1.000 & $1.000(1.000$ to 1.000$)$ \\
\hline Yes & $1(5.0 \%)$ & $1(5.0 \%)$ & & & \\
\hline \multicolumn{6}{|c|}{ Terminal myelocystocele } \\
\hline No & $18(90.0 \%)$ & $18(90.0 \%)$ & $0.000^{*}$ & 1.000 & 1.000 (1.000 to 1.000$)$ \\
\hline Yes & $2(10.0 \%)$ & $2(10.0 \%)$ & & & \\
\hline \multicolumn{6}{|l|}{ Spinal lipoma } \\
\hline No & $17(85.0 \%)$ & $18(90.0 \%)$ & $0.229^{*}$ & 0.632 & 0.773 (0.350 to 1.000$)$ \\
\hline Yes & $3(15.0 \%)$ & $2(10.0 \%)$ & & & \\
\hline \multicolumn{6}{|c|}{ Lipoma of the filum terminale } \\
\hline No & $17(85.0 \%)$ & $17(85.0 \%)$ & $0.000^{*}$ & 1.000 & 1.000 (1.000 to 1.000$)$ \\
\hline Yes & $3(15.0 \%)$ & $3(15.0 \%)$ & & & \\
\hline \multicolumn{6}{|l|}{ LDM } \\
\hline No & $17(85.0 \%)$ & $18(90.0 \%)$ & $0.229^{*}$ & 0.632 & 0.773 (0.350 to 1.000$)$ \\
\hline Yes & $3(15.0 \%)$ & $2(10.0 \%)$ & & & \\
\hline \multicolumn{6}{|l|}{ DST } \\
\hline No & $19(95.0 \%)$ & $19(95.0 \%)$ & $0.000^{*}$ & 1.000 & 1.000 (1.000 to 1.000$)$ \\
\hline Yes & $1(5.0 \%)$ & $1(5.0 \%)$ & & & \\
\hline \multicolumn{6}{|c|}{ DST with meningitis } \\
\hline No & $19(95.0 \%)$ & 20 (100.0\%) & $1.026^{*}$ & 0.311 & 0 (0.000 to 0.000$)$ \\
\hline Yes & $1(5.0 \%)$ & $0(0.0 \%)$ & & & \\
\hline \multicolumn{6}{|c|}{ Tight filum terminale } \\
\hline No & $18(90.0 \%)$ & $18(90.0 \%)$ & $0.000^{*}$ & 1.000 & 1.000 (1.000 to 1.000$)$ \\
\hline Yes & $2(10.0 \%)$ & $2(10.0 \%)$ & & & \\
\hline \multicolumn{6}{|c|}{ Persistent terminal ventricle } \\
\hline No & 19 (95.0\%) & 20 (100.0\%) & $1.026^{*}$ & 0.311 & 0 (0.000 to 0.000$)$ \\
\hline Yes & $1(5.0 \%)$ & $0(0.0 \%)$ & & & \\
\hline \multicolumn{6}{|l|}{ CRS } \\
\hline No & $17(85.0 \%)$ & $17(85.0 \%)$ & $0.000^{*}$ & 1.000 & 1.000 (1.000 to 1.000$)$ \\
\hline Yes & $3(15.0 \%)$ & $3(15.0 \%)$ & & & \\
\hline \multicolumn{6}{|c|}{ Diastematomyelia } \\
\hline No & 19 (95.0\%) & $19(95.0 \%)$ & $0.000^{*}$ & 1.000 & 1.000 (1.000 to 1.000$)$ \\
\hline Yes & $1(5.0 \%)$ & $1(5.0 \%)$ & & & \\
\hline
\end{tabular}

$P$ value $>0.05$ : non significant; $P$ value $<0.05$ : significant; $P$ value $<0.01$ : highly significant

${ }^{*}$ Chi-square test

found full, partial, and no agreement in $84.8 \%, 9.1 \%$, and 6.1\%. While Tawfik [12], Dhingani [13], and Kommana [10] et al. found full agreement in $88 \%, 79.3 \%, 62.5 \%$, partial agreement in $12 \%, 20.7 \%, 25 \%$, and no agreement in $66.7 \%$ (patients > 2 yrs.), $0 \%, 12.5 \%$, respectively. 
Table 6 Detailed agreement between USG and MRI findings regarding detection of segmentation/vertebral spine anomalies

\begin{tabular}{|c|c|c|c|c|c|}
\hline $\begin{array}{l}\text { Type of spinal } \\
\text { dysraphism }\end{array}$ & $\begin{array}{l}\text { MRI } \\
\text { No. (\%) }\end{array}$ & $\begin{array}{l}\text { Ultrasound } \\
\text { No. (\%) }\end{array}$ & Test value & $P$ value & Kappa agreement $(95 \% \mathrm{Cl})$ \\
\hline \multicolumn{6}{|c|}{ Segmentation/vertebral spine anomalies } \\
\hline No & $13(65.0 \%)$ & $16(80.0 \%)$ & $1.129^{*}$ & 0.288 & 0.634 (0.279 to 0.989 ) \\
\hline Yes & $7(35.0 \%)$ & $4(20.0 \%)$ & & & \\
\hline
\end{tabular}

$P$ value $>0.05$ : non-significant; $P$ value $<0.05$ : significant; $P$ value $<0.01$ : highly significant

${ }^{*}$ Chi-square test

Regarding the missed USG findings in cases of partial agreement, we and Dhingani et al. [13] both similarly missed cases of tethered cord and intradural lipoma.

Most of the missed cases in our study, limiting the accuracy of USG, were in patients above 6 months of age. However, Jehangir et al. [16] also mentioned that despite the higher detection rates of spinal anomalies by MRI, this has not reflected on surges in surgical intervention. Hence, the significance of those spinal anomalies missed by USG, is still uncertain.

It is important to note that we revealed from our study relatively lower USG sensitivity levels $(57.1 \%)$ in cases of segmentation/vertebral spine anomalies, USG showed particularly better diagnostic yield in cases of complete agenesis of the spine, such as sacral agenesis. Whereas USG lagged in cases of segmentation spine anomalies, such as butterfly hemivertebrae, or partial hemi-sacral agenesis.

Interestingly enough, we encountered in our study a diagnostic dilemma when differentiating between DST and LDM on imaging. However, guided by the Lee et al. study [24], we managed to solve this dilemma, using their concluded LDM distinct imaging features "a visible intrathecal tract with dorsal tenting of the cord at the tract-cord union", whereas DST is commonly associated with infection and dermoid or epidermoid tumors. Moreover, we were also guided by the Pang et al. study [25], in the subclassification of LDM into saccular, flat (non-saccular), and saccular with transitional skin lesion. The latter, as illustrated in Fig. 7, showing "a squamous epithelium-lined bubble on an otherwise flat skin surface when the patient strained".

Despite the high diagnostic accuracy of spinal USG, we still recommend performing high resolution MRI with thin sections in all patients with a sinus tract, to delineate the whole tract length, its exact termination, and site of attachment to the cord. This is because we faced many challenges when trying to delineate the sinus tracts using USG as shown in Fig. 7 and when attempting to assess their complications, such as meningitis and intraspinal abscesses.

In agreement with Hughes et al. [11], we reported another challenge when using USG to distinguish between echogenic lesions and surrounding cauda equina nerve roots that appear thick and echogenic in neonates, thus leading to high false-positive and falsenegative results in such cases as terminal lipomas and fatty fila. Therefore, MRI yields better detection of fatty lesions due to superior tissue characterization.

On the other hand, USG revealed excellent accuracy in the determination of level of conus termination, as well as in the exclusion of cord tethering by examining conus and nerve roots motility by cine B mode and quantified $\mathrm{M}$ mode. Ultrasonography also showed high specificity in differentiating solid and cystic masses with superior characterization of the cystic mass contents (nerve endings, cyst within cyst, multi locules, etc.).

Before we wrap up, we would like to emphasize that screening tests are conducted upon asymptomatic populations to highlight the subgroups at risk who require

\footnotetext{
(See figure on next page.)

Fig. 7 A 45-day-old male infant presented with lower back wide deep cutaneous dimple (crater) with small, discolored swelling mildly enlarging with straining shown in A. B, C Axial and Sagittal T2WI showing left para midline subcutaneous cystic lesion (Asterix) at level of S1/S2 vertebrae with a fibrous tract seen extending deeply passing though S2 spinal bifida into spinal canal. D Sagittal T2WI showing termination of conus medullaris at level of mid L4 vertebral body, hypointense tract is seen traceable in CSF space and separately identified till its attachment in dorsal aspect of conus medullaris (white arrow). E Sagittal T1WI showing tiny hyperintense focus on left side of conus medullaris representing intradural lipoma (white arrow). F Axial USG image at level of tip of conus medullaris showing small echogenic well defined fatty lesion representing intradural lipoma (white arrow). G Sagittal USG image at level of upper S1/S2 vertebral level showing subcutaneous cystic lesion with hypoechoic fibrous tract extending deeply into spinal canal. H Sagittal USG image showing level of termination of conus medullaris at mid L4 vertebral body level. I M mode USG image at level of L5 showing absence of oscillation of cauda equina nerve roots denoting tethered cord. Type of spinal dysraphism: Transitional form of LDM with tethered cord and intradural lipoma
} 


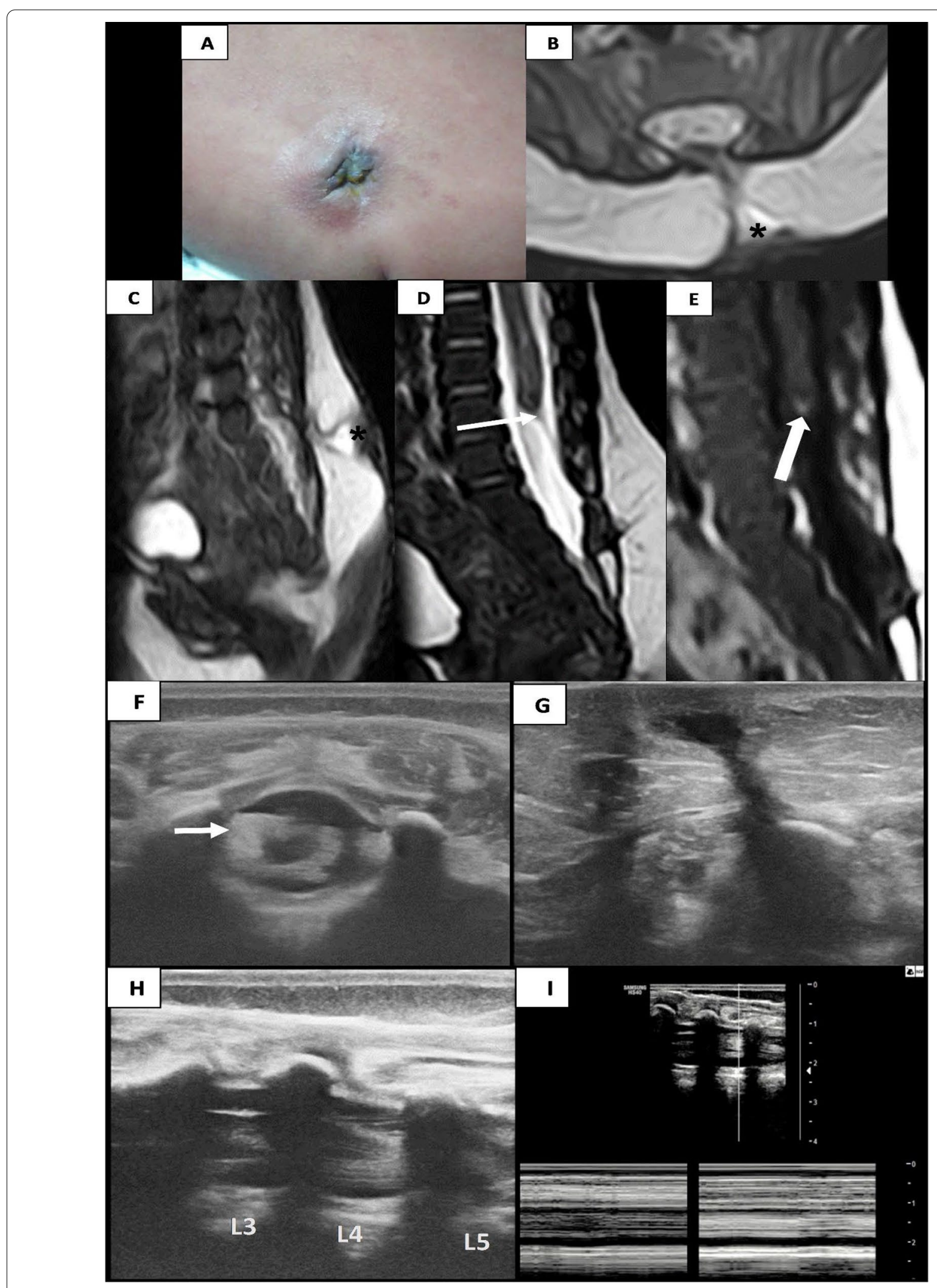

Fig. 7 (See legend on previous page.) 
Table 7 Relation between USG and MRI as regarding diagnosis of each subtype of spinal dysraphism

\begin{tabular}{llllll}
\hline USG & MRI & & Test value & $P$ value & Sig. \\
\cline { 2 - 2 } & No & Yes & & \\
& No. $(\%)$ & No. $(\%)$ & &
\end{tabular}

Tethered cord

$\begin{array}{cccccc}\text { No } & 8(100.0 \%) & 1(8.3 \%) & 16.296^{*} & 0.000 & \text { HS } \\ \text { Yes } & 0(0.0 \%) & 11(91.7 \%) & & & \\ \text { Lipomyelocele } & & & \end{array}$

$\begin{array}{ccllll}\text { No } & 19(100.0 \%) & 0(0.0 \%) & 20.000^{*} & 0.000 & \text { HS } \\ \text { Yes } & 0(0.0 \%) & 1(100.0 \%) & & & \\ \text { Lipomyelomeningocele } & & & \end{array}$

\begin{tabular}{|c|c|c|c|c|c|}
\hline No & $18(100.0 \%)$ & $0(0.0 \%)$ & $20.000^{*}$ & 0.000 & $\mathrm{HS}$ \\
\hline Yes & $0(0.0 \%)$ & $2(100.0 \%)$ & & & \\
\hline \multicolumn{5}{|c|}{ Meningocele } & \\
\hline No & $19(100.0 \%)$ & $0(0.0 \%)$ & $20.000^{*}$ & 0.000 & $\mathrm{HS}$ \\
\hline Yes & $0(0.0 \%)$ & $1(100.0 \%)$ & & & \\
\hline \multicolumn{5}{|c|}{ Myelocystocele } & \\
\hline No & $18(100.0 \%)$ & $0(0.0 \%)$ & $20.000^{*}$ & 0.000 & $\mathrm{HS}$ \\
\hline Yes & $0(0.0 \%)$ & $2(100.0 \%)$ & & & \\
\hline \multicolumn{5}{|c|}{ pinal lipoma } & \\
\hline No & $17(100.0 \%)$ & $1(33.3 \%)$ & $12.593^{*}$ & 0.000 & $\mathrm{HS}$ \\
\hline Yes & $0(0.0 \%)$ & $2(66.7 \%)$ & & & \\
\hline \multicolumn{5}{|c|}{ ipoma of the filum terminale } & \\
\hline No & $17(100.0 \%)$ & $0(0.0 \%)$ & $20.000^{*}$ & 0.000 & $\mathrm{HS}$ \\
\hline Yes & $0(0.0 \%)$ & $3(100.0 \%)$ & & & \\
\hline \multicolumn{5}{|l|}{ DM } & \\
\hline No & $17(100.0 \%)$ & $1(33.0 \%)$ & $12.593^{*}$ & 0.000 & HS \\
\hline Yes & $0(0.0 \%)$ & $2(66.0 \%)$ & & & \\
\hline \multicolumn{5}{|l|}{ DST } & \\
\hline No & $19(100.0 \%)$ & $0(0.0 \%)$ & $20.000^{*}$ & 0.000 & $\mathrm{HS}$ \\
\hline Yes & $0(0.0 \%)$ & $1(100.0 \%)$ & & & \\
\hline \multicolumn{5}{|c|}{ Meningitis } & \\
\hline No & $19(100.0 \%)$ & $1(100.0 \%)$ & - & - & - \\
\hline Yes & $0(0.0 \%)$ & $0(0.0 \%)$ & & & \\
\hline \multicolumn{5}{|c|}{ ight filum terminale } & \\
\hline No & $18(100.0 \%)$ & $0(0.0 \%)$ & $20.000^{*}$ & 0.000 & $\mathrm{HS}$ \\
\hline Yes & $0(0.0 \%)$ & $2(100.0 \%)$ & & & \\
\hline \multicolumn{5}{|c|}{ Persistent terminal ventricle } & \\
\hline No & $19(100.0 \%)$ & $1(100.0 \%)$ & - & - & - \\
\hline Yes & $0(0.0 \%)$ & $0(0.0 \%)$ & & & \\
\hline \multicolumn{5}{|l|}{ RSS } & \\
\hline No & $17(100.0 \%)$ & $0(0.0 \%)$ & $20.000^{*}$ & 0.000 & $\mathrm{HS}$ \\
\hline Yes & $0(0.0 \%)$ & $3(100.0 \%)$ & & & \\
\hline \multicolumn{5}{|c|}{ Diastematomyelia } & \\
\hline No & $19(100.0 \%)$ & $0(0.0 \%)$ & $20.000^{*}$ & 0.000 & $\mathrm{HS}$ \\
\hline Yes & $0(0.0 \%)$ & $1(100.0 \%)$ & & & \\
\hline
\end{tabular}

$P$ value $>0.05$ : non significant; $P$ value $<0.05$ : significant; $P$ value $<0.01$ : highly significant

${ }^{*}$ Chi-square test
Table 8 Relation between USG and MRI as regarding diagnosis of segmentation/vertebral spine anomalies

\begin{tabular}{llllll}
\hline USG & MRI & & Test value & $P$ value & Sig. \\
\cline { 2 - 2 } & No & Yes & & \\
& No. (\%) & No. (\%) & &
\end{tabular}

Segmentation/vertebral spine anomalies

\begin{tabular}{cccccc} 
No & $13(100.0 \%)$ & $3(42.9 \%)$ & $9.286^{*}$ & 0.002 & HS \\
Yes & $0(0.0 \%)$ & $4(57.1 \%)$ & & & \\
\hline
\end{tabular}

$P$ value $>0.05$ : non significant; $P$ value $<0.05$ : significant; $P$ value $<0.01$ : highly significant

${ }^{*}$ Chi-square test

further assessment. Screening tests are applied unto large populations and hence have to be simple, cost effective, readily available, and non-invasive [16]. Spinal USG is a perfect match that fulfils all the above criteria with reasonable accuracy.

Hence, we finally recommend that the high-risk patients for SD who require appropriate screening, are those patients with ARM, particularly high level and complex types, as well as patients with back cutaneous stigmata, particularly atypical dimples and swellings. Ultrasonography should be used as a front-line screening test. If USG is abnormal, equivocal or technically limited, MRI evaluation is advised.

The main limitations of our study were the small study population, the sparsity of some of the included subtypes of ARMs and back cutaneous stigmata, as well as the inclusion of some older patients with ossified posterior spinal elements.

\section{Conclusion}

We have concluded that spinal USG is a very powerful tool with comparable sensitivity and specificity to MRI. However, its main limitation is the narrow time window prior to the ossification of the posterior spinal elements, after which its diagnostic accuracy falls behind.

Since closed spinal dysraphism usually presents late with symptoms of cord tethering, we recommend USG as a screening (not diagnostic) modality in the neonatal period. We have attempted in our study to specify the high-risk patients endorsed for USG screening.

\footnotetext{
Abbreviations

USG: Ultrasonography; MRI: Magnetic resonance imaging; SD: Spinal dysraphism; OSD: Open spinal dysraphism; CSD: Closed spinal dysraphism; ARM Anorectal malformation; T1Wl: T1-weighted imaging; T2Wl: T2-weighted imaging; STIR: Short inversion recovery; b-FFE: Balanced fast-field echo; TR: Repetition time; TE: Echo time; FOV: Field of view; CRS: Caudal regression
} 
syndrome; LDM: Limited dorsal myeloschisis; DST: Dermal sinus tract; CSF: Cerebrospinal fluid; NSA: Number of signal averages; MHz: Megahertz; mm: Millimeter; ms: Milliseconds; LSS: Lumbosacral spine; PPV: Positive predictive value; NPV: Negative predictive value; IQR: Interquartile range; S: Significant; NS: Non-significant.

\section{Acknowledgements}

The authors would like to thank Dr. Shaimaa AbdelSattar Mohammad for her contribution in the work.

\section{Authors' contributions}

NA helped in preparation of study methodology, data collection and writing the paper. GE participated in formulation of the study, preparation of methodology, data collection, analysis and revision of collected data. NM participated in revision of the study methodology and collected data. KA participated in revision of the study methodology and collected data. All authors read and approved the final manuscript.

\section{Funding}

The authors state that this work has not received any funding from any resource.

\section{Availability of data and materials}

The dataset used and/or analyzed during the current study are available from the corresponding author on reasonable request.

\section{Declarations}

\section{Ethics approval and consent to participate}

The study is approved by Ain Shams University ethical and scientific committee; written informed consent was obtained from all patient's guardians. The reference number is not applicable and/or not available.

\section{Consent for publication}

Consent for publication was obtained from the patient's guardians.

\section{Competing interests}

The authors of this manuscript declare no relationships with any companies, whose products or services may be related to the subject matter of the article.

Received: 4 December 2021 Accepted: 9 February 2022

Published online: 15 February 2022

\section{References}

1. Valente I, Pedicelli A, Piacentini M, Di Serafino M, Vallone G, Speca S, Colosimo C (2019) Spinal cord ultrasonography of the newborn. J Ultrasound 22:113-119. https://doi.org/10.1007/s40477-018-0345-y

2. Ausili E, Maresca G, Massimi L, Morgante L, Romagnoli C, Rendeli C (2018) Occult spinal dysraphisms in newborns with skin markers: role of ultrasonography and magnetic resonance imaging. Child's Nerv Syst 34:285-291. https://doi.org/10.1007/s00381-017-3638-0

3. Reghunath A, Ghasi RG, Aggarwal A (2021) Unveiling the tale of the tail: an illustration of spinal dysraphisms. Neurosurg Rev 44:97-114. https:// doi.org/10.1007/s10143-019-01215-z

4. Balani A, Chatur C, Biswas A, Oztekin O, Mankad K (2020) Spinal dysraphisms: Highlighting discrepancies in the current literature and emphasizing on the need for a consensus. Quant Imaging Med Surg 10:549-553. https://doi.org/10.21037/QIMS.2020.02.04

5. Kumar J, Afsal M, Garg A (2017) Imaging spectrum of spinal dysraphism on magnetic resonance: a pictorial review. World J Radiol 9(4):178-190. https://doi.org/10.4329/wjr.v9.i4.178

6. Rees MA, Squires JH, Coley BD, Hoehne B, Ho ML (2021) Ultrasound of congenital spine anomalies. Pediatr Radiol 50:2442-2457. https://doi.org/ 10.1007/s00247-021-05178-6

7. Orman G, Tijssen MPM, Seyfert D, Gassner I, Huisman TAGM (2019) Ultrasound to evaluate neonatal spinal dysraphism: a first-line alternative to CT and MRI. J Neuroimaging 29:553-564. https://doi.org/10.1111/jon. 12649
8. Totonelli G, Messina R, Morini F, Mosiello G, lacusso C, Randi F, Palma P, Bagolan P, lacobelli BD (2019) Impact of the associated anorectal malformation on the outcome of spinal dysraphism after untethering surgery. Pediatr Surg Int 35:227-231. https://doi.org/10.1007/s00383-018-4400-8

9. Aby J, Kim J, Lai L, Flaherman V, Loyal J (2020) Variation in management of cutaneous lumbosacral findings in newborns. Hosp Pediatr 10:496-501. https://doi.org/10.1542/hpeds.2019-0264

10. Kommana SS, Machavaram V, Kaki R, Bonthu A, Kari S, Rednam IS, Gandi S (2019) Evaluation of paediatric spinal dysraphisms by ultrasonography and magnetic resonance imaging. J Evid Based Med Healthc 6:111-115. https://doi.org/10.18410/jebmh/2019/21

11. Hughes JA, De Bruyn R, Patel K, Thompson D (2003) Evaluation of spinal ultrasound in spinal dysraphism. Clin Radiol 58:227-233. https://doi.org/ 10.1016/S0009-9260(02)00478-6

12. Tawfik NA, Ahmed AT, El-Shafei TE, Habba MR (2020) Diagnostic value of spinal ultrasound compared to MRI for diagnosis of spinal anomalies in pediatrics. Egypt J Radiol Nucl Med 51:18. https://doi.org/10.1186/ s43055-020-0131-7

13. Dhingani D, Boruah D, Dutta H, Gogoi R (2016) Ultrasonography and magnetic resonance imaging evaluation of pediatric spinal anomalies. J Pediatr Neurosci 11:206-212. https://doi.org/10.4103/1817-1745.193374

14. Ruangtrakool R, Kowuttikulrangsee P, Pengvanich P, Phonwijit L (2021) Prevalence and association of occult spinal dysraphism with anorectal malformation. J Med Assoc Thail 104:114-122. https://doi.org/10.35755/ jmedassocthai.2021.01.11521

15. Oh C, Youn JK, Han JW, Yang HB, Kim HY, Jung SE (2020) Analysis of associated anomalies in anorectal malformation: major and minor anomalies. J Korean Med Sci 35:e98. https://doi.org/10.3346/JKMS.2020.35.E98

16. Jehangir S, Adams S, Ong T, Wu C, Goetti R, Fowler A, Sannappa Venkatraman S (2020) Spinal cord anomalies in children with anorectal malformations: ultrasound is a good screening test. J Pediatr Surg 55:1286-1291. https://doi.org/10.1016/j.jpedsurg.2019.09.077

17. Esposito G, Totonelli G, Morini F, Contini G, Palma P, Mosiello G, Longo D, Schingo PM, Marras CE, Bagolan P, lacobelli BD (2021) Predictive value of spinal bone anomalies for spinal cord abnormalities in patients with anorectal malformations. J Pediatr Surg 56:1803-1810. https://doi.org/10, 1016/j.jpedsurg.2021.05.011

18. Minneci PC, Kabre RS, Mak GZ, Halleran DR, Cooper JN, Afrazi A, Calkins CM, Downard CD, Ehrlich P, Fraser J, Gadepalli SK, Helmrath MA, Kohler JE, Landisch R, Landman MP, Lee C, Leys CM, Lodwick DL, Mon R, McClure B, Rymeski B, Saito JM, Sato TT, St. Peter SD, Wood R, Levitt MA, Deans KJ (2018) Screening practices and associated anomalies in infants with anorectal malformations: results from the Midwest Pediatric Surgery Consortium. J Pediatr Surg 53:1163-1167. https://doi.org/10.1016/j.jpeds urg.2018.02.079

19. Resmi MR, Thappa DM, Chandrashekar L, Plakkal N, Ramesh A (2021) A hospital based cross sectional study of midline cutaneous lesions in neonates and its association with spinal dysraphism detected using ultrasound. Indian Dermatol Online J 12:408-411. https://doi.org/10.4103/ idoj.IDOJ_748_20

20. Shields LB, Mutchnick IS, Daniels MW, Peppas DS, Rosenberg E (2021) Risk of occult spinal dysraphism based on lumbosacral cutaneous manifestations. SAGE Open Med 9:1-7. https://doi.org/10.1177/205031212110371 72

21. O'Neill BR, Gallegos D, Herron A, Palmer C, Stence NV, Hankinson TC, Wilkinson CC, Handler MH (2017) Use of magnetic resonance imaging to detect occult spinal dysraphism in infants. J Neurosurg Pediatr 19:217-226. https://doi.org/10.3171/2016.8.PEDS16128

22. Choi SJ, Yoon HM, Hwang JS, Suh CH, Jung AY, Cho YA, Lee JS (2020) Incidence of occult spinal dysraphism among infants with cutaneous stigmata and proportion managed with neurosurgery: a systematic review and meta-analysis. JAMA Netw Open 3:1-11. https://doi.org/10. 1001/jamanetworkopen.2020.7221

23. Elmesallamy WAA (2019) Perioperative ultrasound imaging versus magnetic resonance imaging in management of lumbosacral spinal dysraphisms. Egypt J Neurosurg 34-39:1-6. https://doi.org/10.1186/ s41984-019-0061-8

24. Lee SM, Cheon JE, Choi YH, Kim IO, Kim WS, Cho HH, Lee JY, Wang KC (2017) Limited dorsal myeloschisis and congenital dermal sinus: Comparison of clinical and MR imaging features. Am J Neuroradiol 38:176-182. https://doi.org/10.3174/ajnr.A4958 
25. Pang D, Zovickian J, Wong ST, Hou YJ, Moes GS (2013) Limited dorsal myeloschisis: a not-so-rare form of primary neurulation defect. Child's Nerv Syst 29:1459-1484. https://doi.org/10.1007/s00381-013-2189-2

\section{Publisher's Note}

Springer Nature remains neutral with regard to jurisdictional claims in published maps and institutional affiliations.

\section{Submit your manuscript to a SpringerOpen ${ }^{\odot}$ journal and benefit from:}

- Convenient online submission

- Rigorous peer review

- Open access: articles freely available online

- High visibility within the field

- Retaining the copyright to your article

Submit your next manuscript at $\mathbf{s p r i n g e r o p e n . c o m ~}$ 